\title{
Cause-Specific Mortality by Partnership Status: Simultaneous Analysis using Longitudinal Data from England and Wales
}

\author{
Sebastian Franke ${ }^{1,2}$ and Hill Kulu ${ }^{3}$
}

1Department of Geography and Planning, School of Environmental Sciences University of Liverpool Roxby Building, Liverpool, L69 7ZTUK

2Fachbreich Health Services Management, Ludwig-Maximilians-Universität München, Geschwister-Scholl-Platz 1, 80539 München

3School of Geography and Sustainable Development, University of St Andrews, Irvine Building, North Street, St Andrews, KY16 9AL

Corresponding Author's Email: Hill.Kulu@st-andrews.ac.uk 


\section{Statements:}

\section{Funding}

Sebastian Franke's research was supported by the Economic and Social Research Council [ES/J500094/1] through the North West Doctoral Training Centre Social Statistics pathway (Ph.D. project: “'Health, Mortality and Partnership Status: Protection or Selection'”).

\section{Competing interests}

There are no competing interests for any author.

\section{Exclusive Licence}

The Corresponding Author has the right to grant on behalf of all authors and does grant on behalf of all authors, an exclusive licence (or non-exclusive for government employees) on a worldwide basis to the BMJ Publishing Group Ltd and its Licensees to permit this article (if accepted) to be published in JECH editions and any other BMJPGL products to exploit all subsidiary rights, as set out in our licence.

\section{Acknowledgements:}

The authors are grateful to Mark Green and three anonymous referees for valuable comments and suggestions on a previous version of this article. Sebastian Franke's research was supported by the Economic and Social Research Council [ES/J500094/1] through the North West Doctoral Training Centre Social Statistics pathway (Ph.D. project: "Health, Mortality and Partnership Status: Protection or Selection'). The permission of the Office for National Statistics to use the Longitudinal Study is gratefully acknowledged, as is the help provided by staff of the Centre for Longitudinal Study Information and User Support (CeLSIUS). CeLSIUS is supported by the ESRC Census of Population Programme (Award Ref: ES/K000365/1). The authors alone are responsible for the interpretation of the data. This work contains statistical data from ONS which is Crown Copyright. The use of the ONS statistical data in this work does not imply the endorsement of the ONS in relation to the interpretation or analysis of the statistical data. This work uses research datasets which may not exactly reproduce National Statistics aggregates. 


\title{
Cause-Specific Mortality by Partnership Status: Simultaneous Analysis using Longitudinal Data from England and Wales
}

\begin{abstract}
Background: This paper examines cause-specific mortality by partnership status. Although nonmarital cohabitation has rapidly spread in industrialised countries, only a few studies have investigated mortality by partnership status and no recent study has investigated cause-specific mortality by partnership status.
\end{abstract}

Methods: We use data from the ONS Longitudinal Study and apply competing risks survival models.

Results: The simultaneous analysis shows that married individuals have lower mortality than nonmarried from circulatory, respiratory, digestive, alcohol and accident related causes of deaths, but not from cancer. The analysis by partnership status reveals that once we distinguish pre- and postmarital cohabitants from other non-married groups the differences between partnered and nonpartnered individuals become even more pronounced for all causes of death; this is largely due to similar cause-specific mortality levels between married and cohabiting individuals.

Conclusions: With declining marriages rates and the spread of cohabitation and separation a distinction between partnered and non-partnered individuals is critical to understand whether and how having a partner shapes the individuals' health behaviour and mortality. The cause-specific analysis supports both the importance of selection into partnership and the protective effect of living with someone together.

Keywords: mortality, marriage, cohabitation, partnership status, divorce, survival analysis, competing-risks models, England 


\section{Summary Box}

What is already known on this subject

- Married people have better health and lower mortality levels than non-married individuals.

- Married individuals have lower mortality from circulatory and respiratory diseases as well as from accidents and self-harm.

- Marriage rates have significantly declined in many industrialised countries over the last decades; in contrast, pre- and post-marital cohabitation have rapidly spread.

- However, most research on mortality by partnership status does not distinguish between singles and cohabitants treating them as one group; these studies are likely to underestimate mortality differences between partnered and non-partnered individuals and increasingly misrepresent the changing demographic reality.

What this study adds

- Married individuals have lower mortality from all causes with the exception of cancer.

- Once we distinguish cohabitants from other non-married groups the differences between partnered and non-partnered individuals become even more pronounced for all causes of deaths.

- For most of the causes, patterns are similar for cohabiting and married men and women suggesting that having a partner is an important indicator and determinant of health behaviour.

- With declining marriages rates and the spread of cohabitation and separation a distinction between partnered and non-partnered individuals is critical to understand whether and how having a partner shapes the individuals' health behaviour and mortality. 


\section{Introduction}

Research shows that married people in industrialised countries have lower mortality levels than non-married individuals.[1-9] However, it is far from clear whether mortality differences by marital status are explained by the protective effects of marriage or the selection into marriage.[1012] Many studies suggest that a combination between both protection and selection plays a role.[4, 9, 13] Health influences selection into marriage at younger ages, but mortality differences at older ages are also observed due to the cumulation of the protective effects of marriage. $[9,14-16]$

Although there is a large body of literature on mortality differences by marital status, mortality by causes of death have received much less attention. Previous studies show lower mortality rates for married individuals from circulatory and respiratory diseases as well as from accidents and self-harm. For cancer, research demonstrates the higher mortality risk for divorced in comparison to married people.[2, 17-21] However, most research on mortality by partnership status does not distinguish between singles and cohabitants treating them as one group. These studies are likely to underestimate mortality differences between partnered and non-partnered individuals and increasingly misrepresent the changing demographic reality.[16]

Marriage rates have significantly declined in many industrialised countries showing the postponement of marriages combined with some decline of the percentage who marry.[22] In Britain, the median age of marriage for women born in the 1940s and 1950s was in the low twenties, whereas the same figure for cohorts born in the 1970s was in the low thirties; the share of married individuals declined from $90 \%$ among women born in the 1940s and 1950s to 80\% among women born in the 1960s. [23] In contrast, pre- and post-marital cohabitation have rapidly spread over the last decades. While only $10 \%$ of the individuals who were born in the 1940s ever cohabited by age 45 , more than $50 \%$ of the women who were born in the 1960 s cohabited by the 
age of 30. For the younger cohorts, the percentage of individuals having ever cohabited by age 30 is about 70\%.[4, 23, 24] Divorce and separation levels have also increased. One-fifth of the marriages that were formed in the 1965-74 period ended in divorce before their 15th anniversary, whereas more than one-third of marriages have experienced separation in the marriage cohorts of 1995 and later. Separation levels have been even higher among cohabitants.[23] Significant changes in partnership patterns in industrialised countries suggest that any analysis of mortality differences by partnership should distinguish non-marital cohabitants from single and divorced individuals and treat them as a separate group.

The aim of this study is to investigate cause-specific mortality by partnership status. We build on previous research and extend it in two ways. First, we move beyond the non-marriedmarried dichotomy and treat cohabitants as a separate group. Distinguishing cohabitants from other non-married groups (i.e. single and divorced) in the cause-specific analysis of mortality is the first novelty of the study. Previous studies have either examined cause-specific mortality by marital status (e.g. [2, 3, 17, 25-31]) or all-cause mortality by partnership status (e.g. [14, 16, 32-34]). There are very few (if any) recent studies which investigate mortality by causes of death by partnership status.

Second, we conduct simultaneous analysis of cause-specific mortality allowing to explicitly distinguish the contribution of different causes to the all-cause mortality by partnership status. Simultaneous analysis is the second novelty of the paper; most previous studies on mortality by marital status have conducted separate analysis for each cause of death. We calculate causespecific mortality rates by partnership status separately for men and women to compare the mortality risk of selected causes of death. We standardize the mortality rates to socioeconomic characteristics of individuals to examine mortality differences between non-married cohabiting 
and non-married not-cohabiting people. We show how all-cause mortality differences by partnership status in Britain translate into cause-specific mortality differences.

\section{Data and Methods}

\section{Data}

We use the ONS Longitudinal Study (ONS LS), which is a one percent sample of the population of England and Wales (see [35] for more detail). We study cause-specific mortality of the population aged 30-85 between the 2001 and 2011 census. The ONS LS provides demographic and socio-economic characteristics from the 2001 census, linked with yearly death and embarkation events. Our analysis was conducted for men $(158,061)$ and women $(171,706)$ separately. Individuals who leave the study at a known or unknown embarkation date before 2011 are all censored after 3.9 years based on the sensitivity analysis by Franke and Kulu.[16]

\section{Methods}

We use competing risks survival analysis. The cause-specific hazard function, $\boldsymbol{h}_{\boldsymbol{k}}(\boldsymbol{t})$, is defined as follows:

$$
h_{k}(t)=\lim _{\Delta t \rightarrow 0} \frac{\operatorname{Pr}(t \leq T<t+\Delta t, D=k \mid T \geq t)}{\Delta t}, k=1,2 \ldots, K,
$$

where $\boldsymbol{D}$ denotes the cause of death with $\boldsymbol{k}$ as the number of different causes and $\boldsymbol{T}$ represents the duration of an episode or an individual's age. We define a cause-specific proportional hazards regression model to study mortality by partnership status and cause of death.

$$
\ln h_{k}(t)=\ln h_{k, o}(t)+\sum_{l} \beta_{k l} x_{l}(t)+\gamma_{k} z
$$


where $\boldsymbol{h}_{\boldsymbol{k}}(\boldsymbol{t})$ denotes an individual's hazard of mortality and $\boldsymbol{h}_{k, 0}(\boldsymbol{t})$ is the baseline mortality risk for cause $\boldsymbol{k}$ at age $\boldsymbol{t} ; \boldsymbol{x}(\boldsymbol{t})$ is a variable measuring individual socioeconomic characteristics and $\boldsymbol{\beta}$ is the parameter estimate for this variable, with $l$ variables; $y k$ represents the effect of variable $z$ (partnership status) on mortality from cause $\boldsymbol{k}$.

The advantage of the model defined in equation 2 is that the effect of age and all (other) covariates on mortality can vary by cause; however, the contribution of each cause to mortality by partnership status (our covariate of interest) is not easy to grasp from separate models. We extend this model to also measure the relative contribution of each cause to mortality variation by partnership status:

$$
\ln h_{k}(t)=\ln h_{o}(t)+\sum_{l} \beta_{l} x_{l}(t)+\gamma_{k} z
$$

The model defined by equation 3 , is similar to the one defined by equation 2 , but assumes a common baseline for all causes and the same effect of control variables across the causes. Only the effect of partnership status is allowed to vary by cause; $y_{k}$ is a cause-specific parameter for variable $z$, partnership status. The partnership status differences obtained are now directly comparable to the equivalent differences for all-cause mortality.

We use a Cox proportional hazards model to estimate relative risks by partnership status, without having to define the baseline hazard. We need to extend our data, so that we have $k$ records per person with $k$ being the number of possible causes. If an individual died from cause $k$ then our event variable has value 1 for this record (e.g. CVD); for all other records of this individual the variable has value 0 (e.g. cancer). We interact the cause of death variable with partnership status to simultaneously model cause-specific mortality among the population. We can then present mortality rates from each cause by partnership status (e.g. cancer for singles) relative to a reference 
category (e.g. CVD for married people). This approach has become common in some areas of mortality research,[36] but has not yet been used to study mortality by partnership status.

\title{
Causes of death
}

Ideally, one would like to analyse causes of death as detailed as possible. However, this is not feasible due to: a) a small number of events per partnership status when using a detailed cause classification; and b) the independence rule of competing risks. When analysing cause-specific mortality within a competing risk setting, the independence of those causes needs to be ensured. This means that the probability of two causes of death between $(t, t+\Delta t)$ should be negligible. One way to ensure this is to use broad disease categories.[37]

We used the World Health Organisation's tenth version of the International Classification of Diseases (ICD10) (see Table 1 for more detail) to group our causes into the following categories - circulatory diseases, cancer (or malignant neoplasm), respiratory diseases, digestive disease and nervous system diseases; which comprise $85 \%$ of all deaths for the age group 30-85. We fitted additional models including accidents and self-harm and alcohol-related, but we discuss these only briefly.

\author{
Table 1 here
}

\section{Covariates}

For all our models the first covariate is the interaction between marital status and cause of death. Marital status is hereby defined as 'married', 'single', 'divorced/separated', and 'widowed'. In the model that also includes cohabitation, partnership status is defined as 'married', 'single' (not cohabiting), 'divorced/separated' (not cohabiting), 'widowed' (not cohabiting), 'premarital 
(cohabitation)' (cohabiting singles), and 'postmarital (cohabitation)' (cohabiting divorced/separated and widowed).

Control variables are as follows: country of birth ('England and Wales', 'Scotland or Northern Ireland', and 'Others'); ethnicity ('White', 'White mixed', 'Asian', 'Black', 'Chinese' and 'Other'); education ('No qualification', 'Low qualification', 'Medium qualification', 'High qualification', and 'Missing'); and socio-economic status ('Higher managerial and professional occupations', 'Lower managerial and professional occupations', 'Intermediate occupations (clerical, sales, service)', 'Small employers and own account workers', 'Lower supervisory and technical occupations',' Semi-routine occupations', 'Routine occupations', and 'Others'). We also include in the analysis two variables on living arrangements: household size (' 1 person', '2 persons', '3 persons', '4 persons', '5 and more persons' and 'Unknown') and the presence of dependent children ('No children', 'Dependent children', 'Non-dependent children', 'Not applicable').

\section{Results}

Mortality by marital status by five causes

We analysed mortality by marital status by five main causes: circulatory diseases, cancer, respiratory diseases, digestive diseases and nervous system diseases, and observed the following patterns. For both sexes, circulatory diseases and cancer are the leading causes of death, followed by respiratory and other diseases. The risk of dying from one of the latter two is only a half of the risk of dying from a circulatory disease. Non-married individuals have higher mortality from all causes, with the exception of cancer for singles and widowed and nervous system diseases for 
divorced and widowed (Figure 1). Although there is some variation between males and females, overall the patterns are relatively similar.

Figure 1 here "Comparative cause-specific mortality risk for men and women aged 30-85" (description: Risk for 5 causes compared to married-circulatory disease, Source: ONS LS, Authors own calculation)

Mortality by partnership status by seven causes

In the following step, we extended the analysis in two ways. First, we added accidents (including self-harm) and alcohol-related causes. Second, we fitted one model with marital status and one model with partnership status separately for males and females. Comparing the results of the marital status model from the seven-cause analysis (dots in Figure 2) with those of the five-cause analysis (dots in Figure 1) we observe the following. The inclusion of alcohol-related diseases in the analysis leads to a decline in digestive system diseases. The inclusion of accidents results in a decrease in the 'Other causes' category. For both causes of death single and divorced individuals have a significantly higher risk of dying than married people.

Figure 2 here "Comparative cause-specific mortality risk by marital and partnership status for men and women aged 30-85"

(description: Risk for 7 causes compared to married-circulatory disease, Source: ONS LS, Authors own calculation)

Next, we compared the results of the models for marital status and partnership status. For most causes the differences between partnered and non-partnered individuals (triangles in Figure 2) are bigger than those between married and non-married people (dots in Figure 2). This is largely due to distinguishing cohabitants from singles in our analysis. For all causes but cancer and alcoholrelated diseases, we find for men a significantly lower mortality risk for pre-marital cohabitants compared to non-cohabiting singles as well as lower risks for post-marital cohabitants than for non-cohabiting divorced/widowed individuals. The results for women support a clear mortality 
difference between partnered and non-partnered individuals for the circulatory, respiratory and the other disease category.

The effects of covariates were largely as expected (results available upon request). Mortality levels were lower among individuals with higher educational level and social class, and among ethnic minorities as well as migrants from outside the UK; there were no significant mortality differences by household size and the number of dependent children. Mortality levels of control variables were similar to the effects found in the all-cause-mortality models by Franke and Kulu.[16] As these covariates are cause independent, a deviation from the overall-mortality model would suggest a non-independence of the causes used in the competing risks model.

\section{Summary and discussion}

This study investigated cause-specific mortality by marital and partnership status distinguishing between partnered and non-partnered individuals. Distinguishing cohabitants from singles in the cause-specific analysis of mortality was the first novelty of the study. Another novelty was the simultaneous analysis of cause-specific mortality to distinguish the contribution of different causes to the all-cause mortality differences by partnership status. The analysis of mortality by marital status showed that married individuals have lower mortality from all causes with the exception of cancer. Differences by marital status, and thus the relative contribution towards all-cause mortality differences, are the highest for circulatory, respiratory, digestive, alcohol and accident related causes of deaths. The analysis by partnership status showed that once we distinguish cohabitants from other non-married groups the differences between partnered and non-partnered individuals become even more pronounced for almost all causes of deaths. Increased differences between 
partnered and non-partnered individuals are largely due to similar cause-specific mortality between married and cohabiting individuals, although the latter is a topic, which requires further investigation using a larger sample.

The study demonstrates the importance of cause-specific analysis and distinguishing between partnered and non-partnered individuals. With declining marriages rates and the spread of cohabitation and separation such a distinction is critical to understand whether and how having a partner shapes the individuals' health behaviour and mortality. Like previous studies, we observed significant mortality differences by partnership status for circulatory and respiratory systems for both men and women (e.g. [2, 17, 20]). Clearly, our study showed that those differences are underestimated if cohabitants are not distinguished from single and divorced individuals. Additionally, we extended previous research by distinguishing alcohol-related deaths, which can be due to short-term influence like alcohol poisoning or accidents, or long-term influence like alcohol related damage to the digestive or nervous systems. The majority of alcohol related causes in our study was attributed to digestive system diseases. The analysis showed a clear marital/partnership advantage. Further, single and divorced individuals, especially men had a higher risk of death due to accidents and self-harm. As these differences can be attributed to differences in life-style and the short as well as long-term health behaviour, we can argue that having a partner provides protection from health damaging behaviour.

Advantage of having a partner or a spouse was not found for malignant neoplasm (cancer). Cancer became the number one cause of death in the UK in 2011, mostly due to a larger decline in circulatory diseases.[38] Thus, for cancer our analysis shows no advantage of people living with a partner in comparison to those living without a partner. Lower cancer mortality found in singles are more likely due to higher prevalence of other causes rather than the singlehood being a 
protection for cancer. Although we have mostly emphasised the importance of the protective effect of having a partner, relatively high mortality from nervous system diseases observed among nonpartnered individuals supports the idea of selection into partnership by health status.

With circulatory diseases being the main cause of death, a decline in CVD mortality is expected to lead to a decline in overall mortality differences by partnership status. Previous research has suggested that mortality differences by partnership status may gradually disappear. Crucially, our findings show that there are still significant mortality differences by partnership status, for example, in respiratory diseases. Thus, a continued increase in life expectancy, as well as a continued decline in circulatory disease mortality, will not necessarily result in declining mortality gap between partnered and non-partnered individuals.

In this study, survival models used the partnership status as recorded in the 2001 and 2011 Censuses since there is no information on partnership changes in the ONS LS. Methodologically, the simultaneous analysis of causes used in this study assumes a cause independent baseline hazard, which is the same as the all-cause mortality baseline hazard. It is possible that different causes of death have different baseline hazards. In our preliminary analysis, we fitted separate models for the main causes of death - the baseline and covariate effects were thus cause-specific. Most importantly, we observed similar cause-specific mortality differences by partnership status between separate and simultaneous analysis supporting that the results of our simultaneous analysis are robust.

In a competing risks setting with $N$ competing causes only the first failure are observed. We grouped the causes of death up to seven big groups under the assumption that they are independent of each other. The independent assumption has the advantage that survival function of a specific cause derived from the joint-survival function or multiple decrement function of all 
competing risks is reduced to a cause-specific survival function where we can simply censor failures due to different causes. This is so because censored observations do not change the survival or hazard function as long as they are independent of the estimated failure. A limitation of this approach is that this independence hypothesis is not testable [39]. Future studies could compare the results of different competing risks approaches for cause-specific mortality analysis.

Future analysis on cause-specific mortality risks in England and Wales could also disaggregate the patterns by age (which we did in further analysis, but the analysis suffered from small sample size). Such analysis could also include measures of health differences like morbidity or social deprivation (e.g. [40]). The detailed analysis of mortality and health differences between cohabiting and married individuals is another important avenue to proceed. With the spread of preand post-marital cohabitation among younger cohorts this is increasingly important and also feasible. To conclude, using longitudinal data from England and Wales this study showed, first, that partnered individuals have lower mortality from all causes with the exception of cancer. Second, the differences between partnered and non-partnered individuals became pronounced for all causes of death, once pre- and post-marital cohabitants were distinguished from other nonmarried groups. 


\section{References}

[1] $\mathrm{Hu}$ Y, Goldman N. Mortality differentials by marital status: An international comparison. Demography 1990;27(2):233-50.

[2] Ben-Shlomo Y, Smith GD, Shipley M, Marmot MG. Magnitude and causes of mortality differences between married and unmarried men. J Epidemiol Community Health $1993 ; 47(3): 200-5$.

[3] Johnson NJ, Backlund E, Sorlie PD, Loveless CA. Marital status and mortality: The national longitudinal mortality study. Ann Epidemiol 2000;10(4):224-38.

[4] Murray JE. Marital Protection and Marital Selection: Evidence from a Historical-Prospective Sample of American Men. Demography 2000;37(4):511-21.

[5] Brockmann H, Klein T. Love and death in Germany: The marital biography and its effect on mortality. Journal of Marriage and Family 2004;66(3):567-81.

[6] Murphy M, Grundy E, Kalogirou S. The increase in marital status differences in mortality up to the oldest age in seven European countries, 1990-99. Population Studies 2007;61(3):28798.

[7] Dupre ME, Beck AN, Meadows SO. Marital trajectories and mortality among US adults. Am J Epidemiol 2009;170(5):546-55.

[8] Blomgren J, Martikainen P, Grundy E, Koskinen S. Marital history 1971-91 and mortality 1991-2004 in England \& Wales and Finland. J Epidemiol Community Health 2012;66(1):30-6.

[9] Guner N, Kulikova Y, Llull J. Does Marriage Make You Healthier? CEPR Discussion Paper No. DP10245 2014.

[10] Lillard LA, Panis CWA. Marital Status and Mortality: The Role of Health. Demography 1996;33(3):313.

[11] Rendall MS, Weden MM, Favreault MM, Waldron H. The Protective Effect of Marriage for Survival: A Review and Update. Demography 2011;48(2):481-506.

[12] Su D, Stimpson JP, Wilson FA. Racial Disparities in Mortality Among Middle-Aged and Older Men. Am J Mens Health 2015;9(4):289-300.

[13] Waldron I, Hughes ME, Brooks TL. Marriage protection and marriage selectionProspective evidence for reciprocal effects of marital status and health. Soc Sci Med 1996;43(1):113-23. 
[14] Koskinen S, Joutsenniemi K, Martelin T, Martikainen P. Mortality differences according to living arrangements. Int J Epidemiol 2007;36(6):1255-64.

[15] Ploubidis GB, DeStavola BL, Grundy E. Health differentials in the older population of England: An empirical comparison of the materialist, lifestyle and psychosocial hypotheses. BMC Public Health 2011;11(1):1655.

[16] Franke S, Kulu H. Mortality Differences by Partnership Status in England and Wales: The Effect of Living Arrangements or Health Selection? European Journal of Population 2017;18(3):413.

[17] Ebrahim S, Wannamethee G, McCallum A, Walker M, Shaper AG. Marital Status, Change in Marital Status, and Mortality in Middle-aged British Men. Am J Epidemiol 1995;142(8):834-42.

[18] Maxwell R, Harding S. Mortality of migrants from outside England and Wales by marital status. Popul Trends 1998;(91):15-22.

[19] Trovato F. Nativity, Marital Status and Mortality in Canada*. Can Rev Sociol. 1998;35(1):65-91.

[20] Cheung YB. Marital status and mortality in British women: A longitudinal study. Int J Epidemiol 2000;29(1):93-9.

[21] Wild SH, Fischbacher CM, Brock A, Griffiths C, Bhopal R. Mortality from all cancers and lung, colorectal, breast and prostate cancer by country of birth in England and Wales, 2001-2003. Br J Cancer 2006;94(7):1079-85.

[22] Thomson E. Family complexity in Europe. The ANNALS of the American Academy of Political and Social Science 2014;654(1):245-58.

[23] Hannemann T, Kulu H. Union formation and dissolution among immigrants and their descendants in the United Kingdom. Demographic Research 2015;33:273-312.

[24] Ermisch J, Francesconi M. Cohabitation in Great Britain: Not for long, but here to stay. Journal of the Royal Statistical Society: Series A (Statistics in Society) 2000;163(2):153-71.

[25] BURGOA MAR, Regidor E, RODRIGUEZ C, GUTIERREZ-FISAC JL. Mortality by cause of death and marital status in Spain. Eur J Public Health 1998;8(1):37-42.

[26] Kravdal Ø. The impact of marital status on cancer survival. Soc Sci Med 2001;52(3):35768. 
[27] Martikainen P, Martelin T, Nihtilä E, Majamaa K, Koskinen S. Differences in mortality by marital status in Finland from 1976 to 2000: Analyses of changes in marital-status distributions, socio-demographic and household composition, and cause of death. Population Studies 2005;59(1):99-115.

[28] Ikeda A, Iso H, Toyoshima H, et al. Marital status and mortality among Japanese men and women: The Japan Collaborative Cohort Study. BMC Public Health 2007;7(1):949.

[29] Jaffe DH, Manor O, Eisenbach Z, Neumark YD. The Protective Effect of Marriage on Mortality in a Dynamic Society. Ann Epidemiol 2007;17(7):540-7.

[30] Berntsen KN, Kravdal Ø. The relationship between mortality and time since divorce, widowhood or remarriage in Norway. Soc Sci Med 2012;75(12):2267-74.

[31] Metsä-Simola N, Martikainen P. The short-term and long-term effects of divorce on mortality risk in a large Finnish cohort, 1990-2003. Population Studies 2013;67(1):97-110.

[32] Lund R, Due P, Modvig J, Holstein BE, Damsgaard MT, Andersen PK. Cohabitation and marital status as predictors of mortality—an eight year follow-up study. Soc Sci Med 2002;55(4):673-9.

[33] Scafato E, Galluzzo L, Gandin C, et al. Marital and cohabitation status as predictors of mortality: A 10-year follow-up of an Italian elderly cohort. Soc Sci Med 2008;67(9):145664.

[34] Drefahl S. Do the Married Really Live Longer? The Role of Cohabitation and Socioeconomic Status. Journal of Marriage and Family 2012;74(3):462-75.

[35] Hattersley L, Creeser R. Longitudinal Study 1971-1991. History, organisation and quality of data 1995.

[36] Putter H, Fiocco M, Geskus RB. Tutorial in biostatistics: Competing risks and multi-state models. Stat Med. 2007;26(11):2389-430.

[37] David HA, Moeschberger ML. The theory of competing risks. 1. publ. London u.a.: Griffin [u.a.] 1978.

[38] Statistics ON. Deaths Registered in England and Wales (Series DR), 2011. Newport: Office for National Statistics 2012.

[39] Kalbfleisch JD, Prentice RL. The statistical analysis of failure time data. 2nd ed. Hoboken, N.J: J. Wiley 2002. 
[40] Norman P, Boyle P. Are health inequalities between differently deprived areas evident at different ages? A longitudinal study of census records in England and Wales, 1991-2001. Health Place 2014;26:88-93. 
Table 1: Cause of death categories included in different models

\begin{tabular}{|c|c|c|c|c|c|c|}
\hline Cause & ICD10 Category & Married & Single & Divorced & Widowed & Total \\
\hline Circulatory diseases & I00- I99 & 8142 & 1465 & 1336 & 5009 & 15952 \\
\hline Cancer & $\mathrm{C} 00-\mathrm{C} 97$ & 8620 & 1012 & 1405 & 3006 & 14043 \\
\hline Respiratory diseases & J00-J99 & 2780 & 567 & 575 & 1937 & 5859 \\
\hline Digestive diseases & K00-K93 & 827 & 185 & 182 & 570 & 1764 \\
\hline $\begin{array}{l}\text { Nervous system } \\
\text { diseases }\end{array}$ & G00-G99 & 851 & 157 & 114 & 373 & 1495 \\
\hline Accidents & U509, V01-Y89 & 464 & 180 & 156 & 221 & 1021 \\
\hline Alcohol-related* & $\begin{array}{l}\text { F10, G31.2, G62.1, I42.6, } \\
\text { K29.2, K70, K73, K74, } \\
\text { K86.0, X45, X65, Y15, } \\
\text { Y91 }\end{array}$ & 304 & 116 & 146 & 51 & 617 \\
\hline Other (diseases) & & 2135 & 559 & 364 & 1729 & 4787 \\
\hline Total & & 24123 & 4241 & 4278 & 12896 & \\
\hline
\end{tabular}


Table 2 Relative Mortality Risks by Seven Causes of Death for Control Variables.

\begin{tabular}{|c|c|c|c|c|c|c|c|c|c|c|c|c|c|}
\hline \multirow[b]{2}{*}{ PS status } & \multirow[b]{2}{*}{ Cause } & \multicolumn{3}{|c|}{ Men 30-85 } & \multirow[b]{2}{*}{$\mathbf{R} \mathbf{R}$} & \multirow[b]{2}{*}{ Sig } & \multirow[b]{2}{*}{$\mathrm{Cl}$} & \multicolumn{3}{|c|}{ Women 30-85 } & \multirow[b]{2}{*}{$\mathbf{R} \mathbf{R}$} & \multirow[b]{2}{*}{ Sig } & \multirow[b]{2}{*}{$\mathrm{Cl}$} \\
\hline & & $\mathbf{R R}$ & Sig & $\mathrm{Cl}$ & & & & $\mathbf{R R}$ & Sig & $\mathrm{Cl}$ & & & \\
\hline \multicolumn{14}{|c|}{ Country of Birth } \\
\hline & England \& Wales & 1 & & & 1 & & & 1 & & & 1 & & \\
\hline & Scot. \& N. Ireland & 1.18 & $* * *$ & $(1.09-1.27)$ & 1.18 & $* * *$ & $(1.09-1.27)$ & 1.20 & $* * *$ & $(1.1-1.29)$ & 1.20 & $* * *$ & $(1.1-1.29)$ \\
\hline & Others & 0.95 & & $(0.9-1.01)$ & 0.95 & & $(0.9-1.01)$ & 0.95 & & $(0.9-1.01)$ & 0.95 & & $(0.9-1.01)$ \\
\hline & Missing & 0.40 & & $(0.12-1.32)$ & 0.41 & & $(0.12-1.37)$ & 1.23 & & $(0.28-5.38)$ & 1.24 & & $(0.28-5.43)$ \\
\hline \multicolumn{14}{|l|}{ Ethnicity } \\
\hline & White & 1 & & & 1 & & & 1 & & & 1 & & \\
\hline & White mixed & 1.11 & & $(0.87-1.42)$ & 1.11 & & $(0.87-1.42)$ & 1.02 & & $(0.79-1.32)$ & 1.02 & & $(0.79-1.32)$ \\
\hline & Asian & 0.87 & $* *$ & $(0.79-0.97)$ & 0.87 & $* *$ & $(0.79-0.97)$ & 0.85 & $* *$ & $(0.76-0.96)$ & 0.85 & $* *$ & $(0.76-0.96)$ \\
\hline & Black & 0.76 & $* * *$ & $(0.66-0.88)$ & 0.76 & $* * *$ & $(0.66-0.88)$ & 0.85 & $*$ & $(0.73-1)$ & 0.85 & $*$ & $(0.73-0.99)$ \\
\hline & Chinese & 0.73 & & $(0.53-1)$ & 0.73 & $*$ & $(0.53-1)$ & 0.77 & & (0.54-1.09) & 0.76 & & (0.53-1.09) \\
\hline & Other & 0.56 & $*$ & $(0.35-0.89)$ & 0.55 & $*$ & $(0.35-0.88)$ & 0.63 & $*$ & $(0.4-0.99)$ & 0.63 & & $(0.4-0.99)$ \\
\hline \multicolumn{14}{|l|}{ SES } \\
\hline & Higher managerial & 1 & & & 1 & & & 1 & & & 1 & & \\
\hline & Lower managerial & 1.15 & $* * *$ & $(1.07-1.23)$ & 1.15 & $* * *$ & $(1.07-1.23)$ & 1.16 & $*$ & $(1.01-1.34)$ & 1.16 & $*$ & $(1.01-1.33)$ \\
\hline & Intermediate & 1.18 & $* * *$ & $(1.07-1.31)$ & 1.18 & $* * *$ & $(1.07-1.31)$ & 1.12 & & (0.97-1.29) & 1.12 & & $(0.97-1.29)$ \\
\hline & Small employers & 1.19 & $* * *$ & $(1.1-1.28)$ & 1.19 & $* * *$ & (1.11-1.28) & 1.17 & & $(1-1.37)$ & 1.17 & & $(1-1.37)$ \\
\hline & Lower supervisory & 1.37 & $* * *$ & $(1.27-1.47)$ & 1.37 & $* * *$ & $(1.27-1.47)$ & 1.38 & $* * *$ & $(1.19-1.62)$ & 1.38 & $* * *$ & $(1.19-1.61)$ \\
\hline & Semi-routine & 1.47 & $* * *$ & $(1.36-1.58)$ & 1.46 & $* * *$ & $(1.36-1.58)$ & 1.28 & $* * *$ & $(1.11-1.48)$ & 1.28 & $* * *$ & $(1.11-1.48)$ \\
\hline & Routine & 1.54 & $* * *$ & $(1.44-1.66)$ & 1.54 & $* * *$ & $(1.43-1.66)$ & 1.52 & $* * *$ & $(1.32-1.76)$ & 1.52 & $* * *$ & $(1.32-1.76)$ \\
\hline & Others & 1.85 & $* * *$ & $(1.71-2)$ & 1.84 & $* * *$ & $(1.7-1.99)$ & 1.90 & $* * *$ & $(1.65-2.19)$ & 1.9 & $* * *$ & $(1.65-2.19)$ \\
\hline & Missing & 1.16 & & $(0.72-1.87)$ & 1.18 & & $(0.74-1.91)$ & 2.13 & $* * *$ & $(1.29-3.53)$ & 2.14 & $* * *$ & $(1.29-3.53)$ \\
\hline \multicolumn{14}{|l|}{ Education } \\
\hline & Low qualification & 1 & & & 1 & & & 1 & & & 1 & & \\
\hline & Medium qualification & 1.11 & $*$ & $(1.01-1.21)$ & 1.11 & $*$ & $(1.01-1.21)$ & 0.93 & & $(0.82-1.06)$ & 0.93 & & $(0.82-1.06)$ \\
\hline & High qualification & 0.88 & $* * *$ & $(0.83-0.94)$ & 0.88 & $* * *$ & $(0.83-0.94)$ & 0.88 & $* * *$ & $(0.82-0.95)$ & 0.89 & $* * *$ & $(0.82-0.95)$ \\
\hline
\end{tabular}




\begin{tabular}{|c|c|c|c|c|c|c|c|c|c|c|c|}
\hline & No qualification & 1.20 & $* * *$ & $(1.15-1.25)$ & $1.20 * * *$ & $(1.15-1.25)$ & 1.24 & $* * *$ & $(1.18-1.3)$ & $1.24^{* * *}$ & $(1.18-1.3)$ \\
\hline & Missing & 1.32 & & $(0.82-2.12)$ & 1.30 & $(0.81-2.09)$ & 0.68 & & $(0.42-1.1)$ & 0.68 & $(0.42-1.1)$ \\
\hline \multicolumn{12}{|l|}{ Household size } \\
\hline & 2 Person & 1 & & & 1 & & 1 & & & 1 & \\
\hline & 1 Person & 1.07 & $*$ & $(1.01-1.12)$ & 1.03 & (0.98-1.09) & 0.96 & & $(0.91-1.01)$ & $0.95 *$ & $(0.9-1.00)$ \\
\hline & 3 Person & 0.98 & & $(0.91-1.05)$ & 0.99 & $(0.92-1.06)$ & 1.02 & & $(0.96-1.09)$ & 1.03 & $(0.96-1.09)$ \\
\hline & 4 Person & 0.96 & & $(0.88-1.05)$ & 0.97 & $(0.89-1.06)$ & 1.00 & & $(0.91-1.10)$ & 1.01 & $(0.92-1.10)$ \\
\hline & 5+ Persons & 1.08 & & $(0.97-1.2)$ & 1.08 & $(0.97-1.20)$ & 1.11 & & $(0.99-1.24)$ & 1.11 & $(0.99-1.24)$ \\
\hline & unknown & 2.94 & $* * *$ & $(2.71-3.19)$ & $2.86 * * *$ & $(2.63-3.10)$ & 3.00 & $* * *$ & $(2.79-3.21)$ & $2.96 * * *$ & $(2.76-3.18)$ \\
\hline \multicolumn{12}{|l|}{ Dependent Children } \\
\hline & no children & 1 & & & 1 & & 1 & & & 1 & \\
\hline & dependent & 0.95 & & $(0.86-1.04)$ & 0.93 & $(0.84-1.03)$ & 0.92 & & $(0.83-1.03)$ & 0.90 & $(0.81-1.01)$ \\
\hline & non-dependent & 1.19 & $* * *$ & $(1.10-1.29)$ & $1.15^{* * *}$ & $(1.06-1.25)$ & 1.10 & $*$ & $(1.02-1.19)$ & 1.08 & $(1.00-1.17)$ \\
\hline & not applicable & 1.16 & $* * *$ & $(1.11-1.22)$ & $1.13^{* * *}$ & $(1.08-1.2)$ & 1.06 & & $(0.99-1.13)$ & 1.04 & $(0.98-1.12)$ \\
\hline
\end{tabular}

Source: ONS LS, Authors own calculation; circulatory: circulatory system diseases; respiratory: respiratory system diseases; nervous: nervous system diseases; alcohol: alcohol-related diseases

CI: $95 \%$ confidence intervals

p-value: $*_{-} 0.1, * *-0.05, * * *-0.01$ 

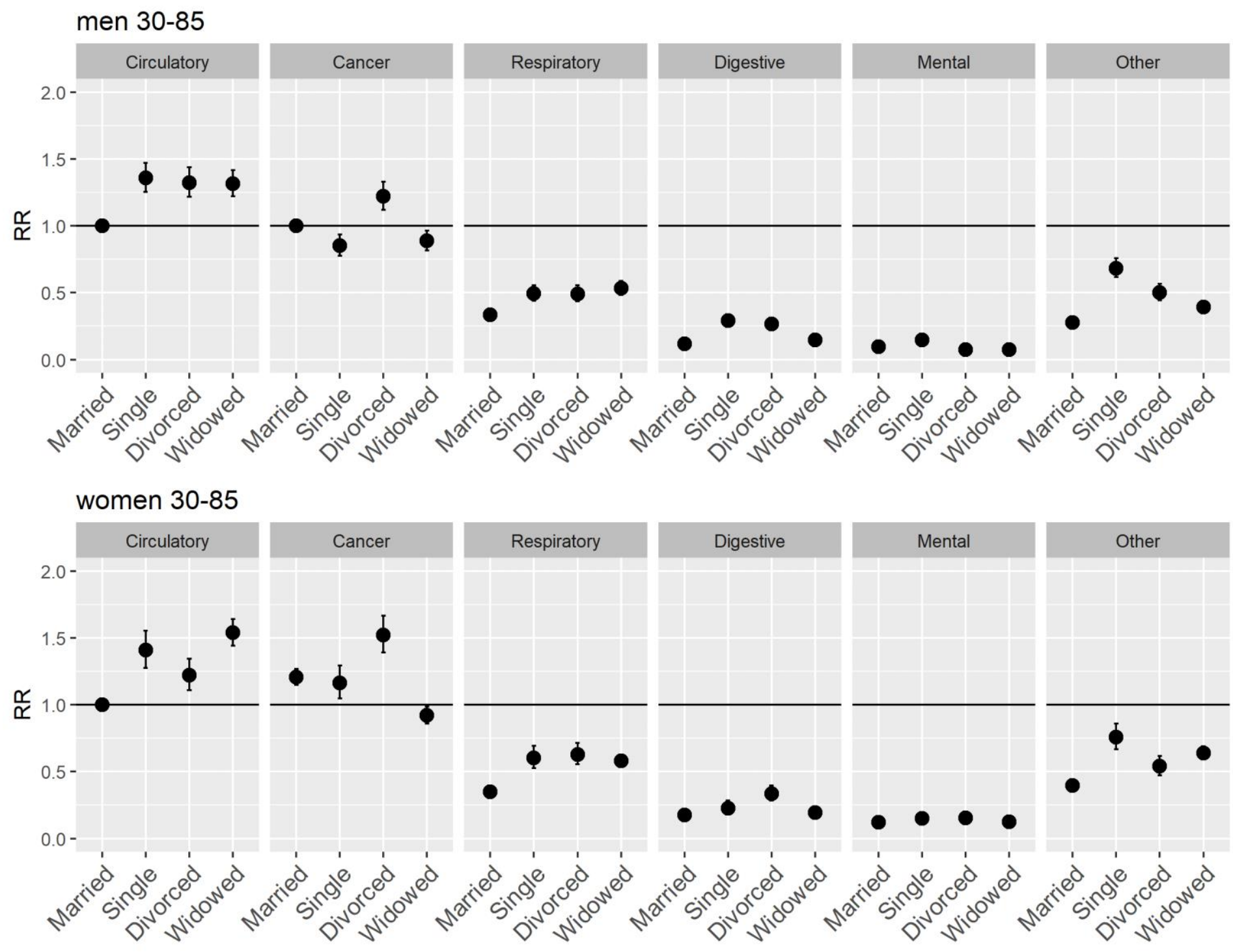

Figure 1 Comparative cause-specific mortality risk for men and women aged 30-85 years (description: risk for five causes compared with married-circulatory disease, source: ONS LS, authors' own calculation). 

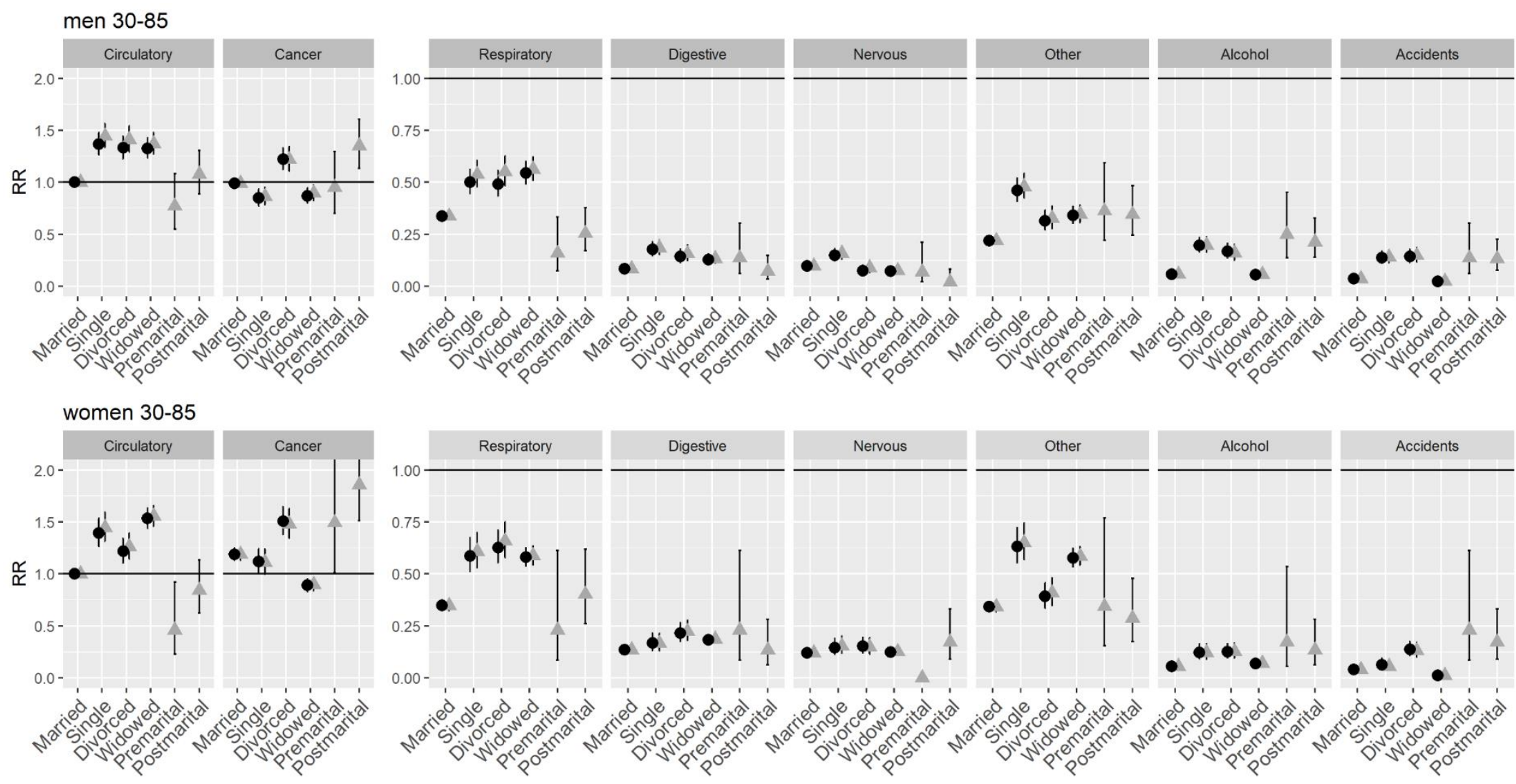

Figure 2 Comparative cause-specific mortality risk by marital and partnership status for men and women aged 30-85 years (description: risk for seven causes compared with married-circulatory disease, source: ONS LS, authors' own calculation). 